\title{
A ADOÇÃO DO PARTO HUMANIZADO E A LEI DA DOULA ${ }^{1}$
}

THE ADOPTION OF HUMANIZED CHILDREN AND THE DOULA LAW

Ana Luísa Scarduelli ASSELLI²

Ana Tereza Jacintho TEIXEIRA ${ }^{3}$

ISSUE DOI: 10.21207/2675-0104.2018.794

\begin{abstract}
RESUMO
O objetivo geral da presente monografia é desvendar formas de violência obstétrica recorrentes nas salas de consulta médica e de parto dos hospitais brasileiros, que são tidas como práticas comuns, e com isso trazer à discussão como essas se normalizaram no entendimento popular, tornando praticamente impunes seus praticantes; trazer à conhecimento formas de combate à violência obstétrica, as medidas jurídicas que podem ser adotadas no apoio às gestantes e os meios de humanizar os partos, ou seja, desvinculá-los de atos violentos. O presente trabalho se dispõe a estudar formas de conscientizar à população de seus direitos enquanto seres humanos no momento em que trazem ao mundo outros seres humanos para que praticas violentas e desnecessárias, que visam a instrumentalização e comercialização do nascer sejam facilmente identificadas, evitadas e senão
\end{abstract}

\footnotetext{
${ }^{1} \mathrm{O}$ presente artigo sintetiza a monografia de conclusão da pesquisa, realizada para o Programa Interno de Bolsas de Iniciação Científica (PIBIC 2017-2018) da Faculdade de Direito de Franca (FDF), Franca/SP.

${ }^{2}$ Discente da Faculdade de Direito de Franca (FDF), Franca/SP. o Programa Interno de Bolsas de Iniciação Científica (PIBIC 2017-2018).

${ }^{3}$ Graduada em História pela Universidade Estadual Paulista Júlio de Mesquita Filho (1972), em Direito pela Faculdade de Direito de Franca (1975), em Estudos Sociais pelo Centro Universitário Barão de Mauá (1975), em Geografia pelo Centro Universitário Barão de Mauá (1979), em Pedagogia pela Universidade de Franca (1984), e Ciências Sociais pela Universidade de Franca (1982). Mestra em Direito Público pela Universidade de Franca (2001) e Doutora em Direito - Universidad Del Museo Social Argentino (2007). Atualmente é professora titular da Faculdade de Direito de Franca e professora titular do Centro Universitário Municipal de Franca, atuando, também, como Chefe de departamento do curso de Ciências Econômicas. Tem experiência na área de Direito, atuando principalmente nos seguintes temas: Brasil, direito, trabalho, responsanbilidade civil e assédio moral.
} 
punidas. Faz-se uma análise sobre a história dos partos, os mitos relacionados à procedimentos adotados e as práticas que evoluíram em alguns pontos e regrediram em outros, através da leitura de livros relativos ao tema, leitura e entendimento da Lei da Doula, avaliação da competência para legislar sobre a atuação das Doulas, análise de casos concretos divulgados em sites confiáveis de comunicação e participação em palestras e cursos de extensão relativos ao tema. Chegando à conclusão de como é de grande importância a correta e ampla significação de "humanização" para que o conceito possa ser inserido no dia a dia de todas as mulheres parturientes, principal foco da pesquisa, de como a sociedade ao passo que evolui tecnológica e economicamente se afasta de sua humanidade, esquecendo a importância da dignidade dos seres, instrumentalizando e valorando economicamente suas vidas, gerando traumas irreparáveis e sem respaldo do Direito Brasileiro para aquelas que de pacientes se tornam vítimas.

Palavras-chave: Parto humanizado. Lei da Doula. Violência obstétrica.

\begin{abstract}
The general objective of this monograph is to uncover recurrent forms of obstetric violence in the medical and delivery rooms of Brazilian hospitals, which are considered as common practices, and with that to bring to the discussion how they normalized themselves in the popular understanding, rendering their practitioners; to bring to the attention ways of combating obstetric violence, the legal measures that can be taken to support pregnant women and the means to humanize childbirth, that is, to free them from violent acts. The present work sets out to study ways of raising the awareness of the population as human beings when they bring other human beings into the world, so that violent and unnecessary practices aimed at the instrumentalization and commercialization of the birth are easily identified, avoided and otherwise punished An analysis of the history of births, the myths related to the procedures adopted and the practices that evolved in some points and regressed in others, through the reading of books related to the subject, reading and understanding of the Law of Doula, evaluation of the competence to legislate on the performance of the Doulas, analysis of concrete cases divulged in reliable sites of communication and participation in lectures and extension courses related to the subject. Finding out how important is the correct and broad meaning of "humanization" so that the concept can be inserted into the day-to-day of all parturient women, the main focus of research, of how society as it evolves technological and economically distances itself from its humanity, forgetting the importance of the dignity of the beings, instrumentalizing and economically valuing their lives, with that, generating irreparable traumas and with little support of the Brazilian Law for those that of patients become victims.
\end{abstract}

Keywords: Humanized delivery. Law of Doula. Obstetric violence.

INTRODUÇÃO

A escolha do presente tema justifica-se pelo grande número de relatos de violência obstétrica nas salas de partos retratados pela mídia nacional e internacional, trazendo à tona uma série de questionamentos jurídicos acerca dos direitos das mulheres enquanto parturientes e consumidoras.

A sociedade se desenvolveu e criou um clima cultural muito propício para que as mulheres, principalmente àquelas com alta grau de escolaridade e que possuem mais acentuado poder de escolhas, decidam opcionalmente por parir de forma cesárea, ou seja, com intervenção cirúrgica. 
Essa cultura se enraizou por meio das influencias médicas, que de fato trouxeram avanços incontáveis para a área da saúde, mas para um público específico, tornando aqueles que podem pagar por determinadas opções detentores do direito de possuir mais dignidade no tratamento que recebem.

O parto, tratado como tabu durante muito tempo pela humanidade, evoluiu em seus aspectos técnicos e medicinais no tocante a higiene, prevenção para momentos emergenciais e possibilidades para aquelas que não poderiam trazer à vida de forma natural.

Entretanto, como se apresentará adiante, a evolução técnica e medicinal do nascer se deu de forma sobreposta à sua evolução humana, tonando-se uma pratica instrumentalizada e voltada à economicidade de tempo e lucro voltada à produtividade médica.

Neste contexto surgiram movimentos sociais organizados por mulheres mães empenhadas a desmistificar receios que estão historicamente ligados aos partos naturais. E outras profissões relacionadas à área da saúde, como as doulas e obstetrizes, voltadas à humanização dos ambientes de parto.

Doula, que significa mulher que serve, é uma profissional que atua durante toda gravidez até o trabalho de parto e pós-parto auxiliando às mulheres a entender mais sobre sua própria gestação, visto que cada pessoa é única, estudando e exercitando formas psicológicas e físicas de sentir-se bem e preparada para o momento do parto.

As doulas em nenhum momento substituem ou podem substituir a presença de um médico, são profissionais distintos e que devem trabalhar em conjunto para que toda gestação encontre um caminho adequado para acontecer da forma mais natural possível.

Por se tratar de uma profissão muito recente é bastante questionada pela classe médica e muitas vezes mal recebida ou barrada em hospitais, que erroneamente desentendem a doula como alguém que pode se enquadrar na Lei do Acompanhante (Lei n ${ }^{\circ} 8.080$ de 19 de setembro de 1990).

A Lei do Acompanhante representou um grande avanço para a humanização dos partos, possibilitando que as parturientes indicassem alguém para que presenciasse todo trabalho de parto e pudesse manifestarse por ela na garantia de seus direitos quando esta pudesse encontrar-se impossibilitada.

Entretanto, a Lei pode ser interpretada de forma excludente quando se trata das profissionais aqui apresentadas, e até mesmo pode 
colidir com a realidade das parturientes que possuem um acompanhante e uma doula para estar presente em seu parto, gerando interrupção do trabalho desenvolvido até então e retirando todo seu sentido.

Visto isso, fez-se necessária a criação de um novo texto que incluísse as doulas no rol de pessoas que possuem o direito de acompanhar as parturientes na sala de parto, sem interferir na atuação médica, mas dando continuidade ao trabalho que desenvolveu durante toda gestação para este momento em especial.

O presente trabalho desenvolveu-se após o conhecimento de que a Lei da Doula estava em processo de votação pela Câmara Municipal de Franca, cidade em que se situa a Faculdade de Direito e foi elaborado através da leitura deste projeto de Lei, consultas bibliográficas, pesquisas online (internet), participação de palestras relacionadas ao tema, conversas informais com doulas do movimento PREMAF e cursos de extensão.

\section{HISTÓRIA E EVOLUÇÃO DO NASCER}

Na cultura ocidental, o parto foi desde logo determinado como um castigo pelo pecado original da carne, sendo momento de expiação da culpa e que deveria ser carregado de dor e sofrimento por seu simbolismo; estes unidos às dificuldades que muitas vezes se encontram na fisiologia humana devido a características anatômicas da espécie geraram a abertura cultural necessária para que aos poucos os partos se tornassem procedimentos médicos.

A assistência ao parto se inicia no momento em que as mulheres começam a auxiliar-se acumulando conhecimentos e experiências para adequar o processo, surgindo a figura das parteiras, mulher dentre estas que possuía a maior experiência sobre o assunto. Conhecidas tradicionalmente como àquelas que prestavam socorro durante os partos domiciliares, as parteiras possuíam conhecimentos passado por gerações e que, portanto, não tinham caráter científico.

As universidades e cursos que profissionalizavam médicos eram direcionadas apenas aos homens que pertenciam as classes mais abastadas da sociedade, estando as parteiras impedidas de frequentá-los, e por ser a gravidez um fato fisiológico diferente de doenças estava excluída do currículo de estudo destes médicos.

No século XVII através de evoluções sociais que se dirigiram para a transformação da obstetrícia os cirurgiões foram incluídos ao 
procedimento de assistência dos partos, mesmo que nenhuma especialização sobre o assunto fosse introduzida à academia.

Os médicos por sua vez, ao dominarem o campo obstétrico o fizeram de forma instrumentalizada, como estudavam nas universidades e cursos sobre outros tipos de cirurgia e devido aos costumes da época não possuíam conhecimento ou envolvimento com o universo feminino equiparáveis aos das parteiras, de forma que até a posição vertical adotada por mulheres de diversas culturas fora trocada pela horizontal, adotada nos demais procedimentos cirúrgicos.

Assim, cedendo o espaço de protagonismo das parturientes e das mulheres que compartilhavam conhecimentos e sentimentos aos médicos que possuíam conhecimentos técnicos e facilidade de ascensão social que surgiu o parto cirúrgico e a quebra das relações interpessoais no momento do nascer.

Os hospitais passaram a simbolizar o ambiente ideal, onde as parturientes encontrariam o acolhimento necessário para sua "hospedagem" durante e pós-parto, acompanhadas por seus médicos e com isso cercadas de toda proteção necessária para que nenhum imprevisto acontecesse.

Estas mudanças sociais e a postura adotada pelos médicos influenciou o psicológico das parturientes para que entendessem o parto como algo a ser temido e às parteiras foi necessária a adaptação aos moldes médicos, tonando-se auxiliares guiadas pelos médicos para seguir a nova tecnologia dos partos. Assim iniciaram-se as atividades profissionais para as mulheres.

A adequação do local em que este se realizaria, trazendo ao cenário do nascer os hospitais, que cada vez mais são equipados de recursos, facilitou a realização dos partos de forma cirúrgica (cesárea), criando a atual cultura que envolve as gestantes de todo Brasil da "cesárea a pedido", comum entre as mulheres de maior nível escolar.

Este clima cultural de cesáreas gerou uma sobrecarga de gastos ao Sistema Único de Saúde (SUS), de forma que o Ministério da Saúde precisou interferir economicamente definindo um porcentual decrescente para o pagamento de cesáreas aos hospitais, reduzindo ou estabilizando as taxas deste tipo de serviço no meio público, movimento oposto do meio privado.

A OMS (Organização Mundial de Saúde) concluiu que esta não é uma situação exclusiva do Brasil, o que gerou a necessidade de se criar uma declaração (de 1998) que determinasse um mínimo possível para a 
intervenção cirúrgica nos partos, recomendand o que deve haver uma razão válida para alterar seu processo natural.

Neste cenário se criou a necessidade de discutir a humanização dos partos. A declaração feita pela OMS foi influenciada por resultados científicos que também levaram em consideração a crescente taxa de mortalidade materna à época, fundamentando-se no valor de reavivar direitos das mulheres à informação e a fazer suas próprias escolhas na área saúde-doença.

As cesáreas vêm se tornando cada vez mais recorrentes tanto em países desenvolvidos quanto em países em desenvolvimento e assim como qualquer cirurgia pode acarretar riscos imediatos e a longo prazo, estes que podem estender seus efeitos da mulher para o bebê e outras gerações principalmente para aquelas mulheres que não têm acesso aos cuidados obstétricos adequados.

Isto posto, comprova-se que a reivindicação e luta de mulheres pela humanização é compatível e apoiada por setores mais avançados da área da saúde, ambos se preocupando com o crescente desequilíbrio tecnológico e econômico em comparação à relação médico-paciente e os frutos que o descontrole destes fatos sociais pode acarretar futuramente.

\section{VIOLÊNCIA OBSTÉTRICA}

A história e evolução do nascer como colocada anteriormente é permeada de movimentos sociais que o moldaram como funciona hoje e neste aspecto é possível perceber a forte influência da cultura machista que predomina no Brasil, objetificando as mulheres e seus partos para que se tornem mecânicos e lucrativos à indústria médica.

A "violência é a imposição de um grau significativo de dor e sofrimento evitáveis. Nesse sentido, destaca-se a violência obstétrica como um tipo específico de violência contra a mulher". A modalidade de violência que aqui se coloca acompanhou mulheres mães durante toda sua história e atualmente possui caráter endêmico, visto o número significativo de casos que se pode perceber através de relatos que chamaram a atenção midiática ultimamente.

A violência obstétrica é psicológica, visto que o grande número de mulheres que optam por realizar um parto cirúrgico o fazem por influência médica mesmo nos casos em que não se faz necessário o 
procedimento, ou seja, através da manipulação de informações profissionais são coagidas pelo medo a realizá-los.

Também pode ser classificada como violência física, visto os procedimentos forçosos e instrumentos desnecessários para realiza-los sem o consentimento da gestante, por exemplo: uso de ocitocina, hormônio que é produzido em quantidade necessária pelo corpo humano, realização da manobra de kristeller (subir sobre a gestante e empurrar sua barriga pratica contraindicada pelo Ministério da Saúde) e o pique, que muitas vezes se faz apenas para poder fechá-lo com o ponto do marido (que possui objetivo de retornar a vagina ao seu aspecto virginal, podendo provocar dificuldades sexuais futuras para a mulher, visando agradar seus maridos).

Recentemente também foi classificada como violência sexual, após o resultado de pesquisas comprovando que o efeito de uma gestação feita por um procedimento forçado à gestante pode gerar nela consequências psicológicas semelhantes à de uma vítima de estupro. Em um artigo escrito para o jornal El País, entrevistando o médico René Castro, que durante 18 anos esteve à frente do Programa de Saúde da Mulher do Ministério da Saúde, Maritxell Freixas relatou:

O doutor Castro alerta que esse tipo de prática tem um impacto emocional. "Tiramos das mães o direito de desfrutar de uma experiência humana, prejudicando os primeiros momentos com seu filho recém-nascido". O especialista reforça citando a tese da psiquiatra e ativista pelos direitos dos bebês e das mães, Ibone Olza. A especialista espanhola afirma que muitas mulheres que sofreram um parto traumático apresentam os mesmos sintomas das vítimas de estupro por sentirem-se "forçadas" a consentir procedimentos "sem terem sido informadas dos riscos dos mesmos". ${ }^{4}$

\subsection{COMERCIALIZAÇÃO DOS PARTOS}

Com advento da cultura de medo que a classe médica instalou no universo feminino surgiram espaços para que a opção majoritária pela forma mecanizada e anestesiada de trazer ao mundo se tornasse um negócio muito lucrativo, automático e frio.

$O$ fato de ser lucrativo está ligado ao tempo que uma mulher levaria para finalizar seu trabalho de parto de forma natural e através de

\footnotetext{
${ }^{4}$ FREIXAS, Meritxell. O abuso silenciado que há por trás das cesáreas. Disponível em: <https://brasil.elpais.com/brasil/2017/08/24/actualidad/1503582688_802126.html>. Acessado em: 17 de julho 2018.
} 
uma cesariana. Enquanto o primeiro pode durar até dez horas e o médico possui função apenas auxiliar e emergencial em alguns casos, o segundo pode levar até duas horas e o médico realizar todas as manobras como principal agente.

Enquanto em um dia pode-se realizar apenas um parto natural, o número de cesáreas e, consequentemente, o quanto se ganha por trazer mais vidas ao mundo em menos tempo poderá ser multiplicado em até 5 vezes nesse mesmo.

O fato de ser um método automático e frio não está relacionado ao fato de que é defesa a ideia de que a mulher tem o dever de sentir dor, mas pelo contrário, objetiva que ela continue sendo a principal atuante do momento em que se torne mãe, podendo escolher qual método gostaria que se aplicasse em seu parto e se quer ou não o conduzir.

\section{QUALIDADE E HUMANIZAÇÃO}

É crescente no Brasil e consciência de cidadania e de direitos pela população que deve ser detentora destes e um dos maiores exemplos é o aumento de queixas nas delegacias de direito do consumidor, onde serviços médicos e de saúde são os mais citados pelos mais diversos motivos e isso acontece por causa da busca populacional por qualidade de assistência, que pode ser palavra usada como sinônimo de humanização.

A avaliação na qualidade de saúde tem-se centrado principalmente sobre dois dos atores desse processo: primeiro busca-se a verificação da adequação das instituições e em segundo a adequação da assistência ao indivíduo e sua satisfação como cliente; é aqui, na avaliação da qualidade do processo em termos de relação interpessoal que se verifica a importância da humanização.

Neste ponto da avaliação têm-se comprovado a maior falha do sistema de saúde: os médicos passaram a supervalorizar a qualidade de desempenho da técnica em detrimento das relações interpessoais, que envolvem a forma de atender e dar atenção aos pacientes enquanto seres humanos.

Não é desejado que seja reduzida a importância das técnicas cirúrgicas ou dos avanços trazidos pela medicina, mas pontuar o distanciamento que houve entre o objetivo genuíno da medicina, qual seja ajudar pessoas no alívio de suas dores físicas ou psicológicas, e a maneira 
como a profissão passou a se desenvolver é forma de recuperar a ligação entre estes pontos cruciais para a qualidade no atendimento médico.

A medicina, considerada normativa e autoritária em relação as suas práticas que com o passar do tempo ganharam ares de bens de consumo, não cuidou de unir a tradição com a humanidade que os pacientes exigem. Os obstetras ludibriados com o "brincar de Deus" que lhes proporciona a profissão acreditam ter a solução para a cultura do medo que cerca os partos: a cirurgia.

O foco em todos os considerados benefícios das cesáreas calou-a sobre seus efeitos prejudiciais, seus custos, todos os objetos, equipe de auxiliares e infraestrutura necessários para que aconteça. Sobretudo, ao indicar cesáreas como o método mais adequado esquecem-se os médicos dos efeitos posteriores, pois a mãe que se torna "paciente" é impedida de maternar seu bebê nos primeiros dias, visto que para todo procedimento cirúrgico é necessário período de recuperação.

A pressa sempre fez parte dos acontecimentos violentos nos partos, a falta de cuidados em pré-natais (quando estes existem), a curta duração de consultas e a pouca atenção que as parturientes recebem durante elas, a antecipação injustificada do parto, a realização dos partos de forma acelerada, ou seja, sem que se espere o tempo do corpo da mulher e a falta de cuidados no pós-parto são algumas das formas de exclusão de tempo, que desencadeia em desumanização o dos processos. Neste sentido a tecnologia funciona como instrumento de desumanização, quando usada apenas para ganhar tempo.

Importante referência quando se trata da humanização dos partos é o especialista Frédérick Leboyer, obstetra francês falecido em 2017, que ficou conhecido pelo livro "Birth Without Violence", publicado em 1975, época em que o autor e médico já se posicionava como defensor da utilização de métodos que ele mesmo instituía como ideais para a realização de um parto mais confortável para a mulher e o bebê.

O método Leboyer ou método de fazer nascer sorrindo, como ficou conhecido após a divulgação de seu livro e aplicação deste em seu trabalho, consiste em alguns cuidados: ambiente quente, com pouca luz e o mínimo de barulho; fazer massagem suave em substituição as palmadas nas costas do bebê recém-nascido; cortar o cordão umbilical após a parada de sua pulsação, facilitando a transição de respiração do recém-nascido; banho no bebê dado pelo pai, ou acompanhante que a mãe escolheu, dado ao lado dela. Estes métodos podem ser aplicados em partos, naturais, 
cesarianos e até dentro da água, tratam-se de pequenos cuidados que fazem a diferença.

\section{AS DOULAS}

Doula é uma palavra que vem do grego e significa "mulher que serve"; designa as mulheres que sem possuir conhecimentos técnicos na área da saúde orientando e assistindo a nova mãe antes, durante e depois de seu parto. A doula oferece conforto, encorajamento, tranquilidade, suporte emocional e físico à gestante. Todos estes através de massagens, preparações físicas, indicações de leitura, conversas, entre outros.

Quando os médicos se dispõem a quebrar paradigmas e processos pré-estabelecidos e entender que existem processos além dos ensinados nas academias, que podem ser ensinados por novos profissionais, como doulas e parteiras, atualmente chamadas de obstetrizes, o conhecimento sobre a humanização se expande.

As doulas adotam métodos considerados mais alternativos para auxiliar as parturientes, por exemplo: cristais, aromaterapia, cromoterapia e plantas medicinais. Muitos desses recursos eram desconhecidos até a última década e geram espantamento no ambiente hospitalar, que pode ser definido com um conjunto de disciplina, rigidez e tradição.

Exemplificou Maria de Lourdes da Silva Teixeira, doula conhecida como Fadynha, em entrevista para elaboração do livro "Humanizando nascimentos e partos", sobre os métodos alternativos que podem ser implementados ao ambiente hospitalar: "Demos uma nova utilidade àquela escadinha que existe em todos os ambientes hospitalares, colocando nela a mulher de cócoras, apoiada por uma pessoa que se senta no degrau mais alto".

A liberdade conquistada pelas parturientes através do trabalho de doulas facilita muito o desenrolar dos partos e consequentemente $\mathrm{o}$ trabalho desempenhado pelos médicos. A parturiente também fica mais satisfeita com seu próprio trabalho e cria laços mais profundos com toda equipe que a auxilia. A maneira como as mulheres vivenciam o trabalho de parto é uma experiência que marca para toda a vida e nela incluem-se as pessoas que fizeram parte dessa experiência de forma negativa ou positiva.

Segundo pesquisas apresentadas na IX Conferência de Parto, realizada em São Francisco, Estados Unidos, em novembro de 1990, pela fisioterapeuta americana Penny Simkin, as parturientes que recebem o 
apoio de uma doula terão lembranças positivas de seus partos, mesmo que não tenha conseguido ter o parto que planejou desde o início do acompanhamento. A presença das doulas faz com que a mulher se sinta cuidada e apoiada.

O consentimento e a recusa informada da gestante são de suma importância durante o trabalho de parto, pois significam o protagonismo da mulher neste, mesmo nos momentos de complicações. A mulher amedrontada bloqueia ocitocina, que é hormônio essencial para o momento do parto, enquanto a mulher segura de si a libera, trazendo seus inúmeros benefícios. Existem pesquisas que concluíram que a doula também faz a liberação desse hormônio durante os partos que presencia.

\subsection{LEI № 11.108, DE 7 DE ABRIL DE 2005}

O Projeto de Lei $\mathrm{n}^{\circ} 8.363 / 2017$ visa modificar a Lei $\mathrm{n}^{\circ}$ $11.108 / 2005$, mais conhecida como "Lei do Acompanhante", possibilitando que a mulher tenha um acompanhante e uma Doula de sua livre escolha, nos momentos pré-parto, do parto e pós-parto, prática descrita como benéfica por estudos que inclusive motivaram ambos os textos legislativos.

As mulheres que recebem apoio contínuo durante o trabalho de parto, tanto no caso dos acompanhantes quanto das Doulas, quando comparadas com as que não possuem, têm mais chance de parto vaginal espontâneo, sem uso de analgesia; tempo de trabalho de parto reduzido; menor insatisfação com a experiência; e um recém-nascido com melhores índices de APGAR.

Mesmo a mulher possuindo esse direito reconhecido por lei de ter consigo um acompanhante, algumas instituições não oferecem espaço para que esse se efetive, apontando, como principais fatores impeditivos: as deficiências de infraestrutura e a falta de preparo do acompanhante, que poderiam, através da aprovação da supramencionada Lei, serem impedimentos supridos pelas exigências legais, gerando a efetivação de um antigo direito conjuntamente com o ganho de um novo direito para as mulheres.

É considerado descumprimento do direito adquirido quando: há impedimento da entrada do acompanhante escolhido pela gestante; há restrição quanto à escolha do acompanhante; só poderia entrar se fosse mulher; só poderia entrar se fosse o pai; há restrição quanto ao tempo; só 
poderia ter acompanhante no pós-parto; só poderia ter acompanhante no pré-parto; só poderia ter acompanhante no parto; só poderia ter acompanhante se fosse parto normal; só poderia ter acompanhante se fosse cesariana; só poderia ter acompanhante durante o horário de visitas; só poderia ter acompanhante durante um período do dia; há cobrança de taxa; há cobrança de taxa para a entrada do acompanhante; há cobrança de taxa para a roupa esterilizada; há cobrança de taxa para a permanência do acompanhante; há cobrança de taxa para o acompanhante pernoitar; há cobrança de taxa para as refeições do acompanhante.

\subsection{PROJETO DE LEI № 8.363, DE 2017}

O projeto de Lei da Doula visa além de sua aprovação proporcionar a discussão acerca da humanização do parto que se insere no contexto da luta pelo fim da violência contra a mulher, ao evidenciar a importância da atuação das doulas para diminuir os altos índices de violência obstétrica, dos excessos de cesarianas desnecessárias, e das outras práticas que causam efeitos físicos e psíquicos irreparáveis.

Várias cidades e Estados brasileiros já se mostraram favoráveis à aprovação da Lei pela Câmara dos Deputados, mas optaram por agir autonomamente acelerando seu processo de aplicação, são exemplos: Santa Catarina, Rio de Janeiro, Paraíba, Pernambuco, Amapá, Amazonas, Tocantins, Rondônia, São Paulo, Acre, Paraná, Minas Gerais, Mato Grosso, Mato Grosso do Sul, Pará Piauí.

Entretanto, a luta pela atuação das Doulas ser aprovada vai além do campo legislativo na câmara onde está sendo discutida e adentra o campo técnico e hospitalar onde terá sua efetividade em caso de aprovação. A classe médica tem se posicionado em maioria contra a aprovação e procurado inclusive barrar a atuação das Doulas nos hospitais, alegando, principalmente, a falta de conhecimentos técnicos para sua atuação. Entretanto, resta comprovada exclusivamente a falta de conhecimento da classe sobre a atuação dessas profissionais e a letra da Lei que busca regulamentá-las, pois não exige tais conhecimentos técnicos. 
O presente tema foi escolhido pelo grande número de relatos de violência obstétrica nas salas de partos retratados pela mídia nacional e internacional, trazendo à tona uma série de questionamentos jurídicos acerca dos direitos das mulheres enquanto parturientes e consumidoras.

O desenvolvimento da sociedade criou um clima cultural muito propício para que as mulheres, principalmente àquelas com alta grau de escolaridade e que possuem mais acentuado poder de escolhas, decidam opcionalmente por parir de forma cesárea, ou seja, com intervenção cirúrgica. Essa cultura se enraizou por meio das influencias médicas, que de fato trouxeram avanços incontáveis para a área da saúde, mas por outro lado influenciaram seu tecnicismo.

A assistência ao parto iniciou-se no momento em que as mulheres começam a auxiliar-se acumulando conhecimentos e experiências para adequar o processo, surgindo a figura das parteiras, mulher dentre estas que possuía a maior experiência sobre o assunto. Conhecidas tradicionalmente como àquelas que prestavam socorro durante os partos domiciliares, as parteiras possuíam conhecimentos passados por gerações e que, portanto, não tinham caráter científico.

No século XVII através de evoluções sociais que se dirigiram para a transformação da obstetrícia os cirurgiões foram incluídos ao procedimento de assistência dos partos, mesmo que nenhuma especialização sobre o assunto fosse introduzida à academia.

Assim, cedendo o espaço de protagonismo das parturientes e das mulheres que compartilhavam conhecimentos e sentimentos aos médicos que possuíam conhecimentos técnicos e facilidade de ascensão social que surgiu o parto cirúrgico e a quebra das relações interpessoais no momento do nascer.

Neste cenário se criou a necessidade de discutir a humanização dos partos. Em declaração feita pela OMS, influenciada por resultados científicos que também levaram em consideração a crescente taxa de mortalidade materna à época, fundamentou-se o valor de reavivar direitos das mulheres à informação e a fazer suas próprias escolhas na área saúde-doença.

As cesáreas vêm se tornando cada vez mais recorrentes tanto em países desenvolvidos quanto em países em desenvolvimento e assim como qualquer cirurgia pode acarretar riscos imediatos e a longo prazo, estes que podem estender seus efeitos da mulher para o bebê e outras gerações principalmente para aquelas mulheres que não têm acesso aos cuidados obstétricos adequados. 
A história e evolução do nascer como colocada anteriormente é permeada de movimentos sociais que o moldaram como funciona hoje e neste aspecto é possível perceber a forte influência da cultura machista que predomina no Brasil, objetificando as mulheres e seus partos para que se tornem mecânicos e lucrativos à indústria médica.

Este cenário abre espaço para que se perceba os diversos casos de violência obstétrica que estão acontecendo e que são de forma: psicológica, física, sexual (pesquisas comprovam que o efeito de uma gestação feita por um procedimento forçado à gestante pode gerar nela consequências psicológicas semelhantes à de uma vítima de estupro) e econômica.

Com advento da cultura de medo que a classe médica instalou no universo feminino surgiram espaços para que a opção majoritária pela forma mecanizada e anestesiada de trazer ao mundo se tornasse um negócio muito lucrativo, automático e frio.

O fato de ser lucrativo está ligado ao tempo que uma mulher levaria para finalizar seu trabalho de parto de forma natural e através de uma cesariana. Enquanto o primeiro pode durar até dez horas e o médico possui função apenas auxiliar e emergencial em alguns casos, o segundo pode levar até duas horas e o médico realizar todas as manobras como principal agente.

Não é desejado que seja reduzida a importância das técnicas cirúrgicas ou dos avanços trazidos pela medicina, mas pontuar o distanciamento que houve entre o objetivo genuíno da medicina, qual seja ajudar pessoas no alívio de suas dores físicas ou psicológicas, e a maneira como a profissão passou a se desenvolver é forma de recuperar a ligação entre estes pontos cruciais para a qualidade no atendimento médico.

Quando os médicos se dispõem a quebrar paradigmas e processos pré-estabelecidos e entender que existem processos além dos ensinados nas academias, que podem ser ensinados por novos profissionais, como doulas e parteiras, atualmente chamadas de obstetrizes, o conhecimento sobre a humanização se expande.

Doula é uma palavra que vem do grego e significa "mulher que serve"; designa as mulheres que sem possuir conhecimentos técnicos na área da saúde orientando e assistindo a nova mãe antes, durante e depois de seu parto. A doula oferece conforto, encorajamento, tranquilidade, suporte emocional e físico à gestante. 
Todos estes através de massagens, preparações físicas, indicações de leitura, conversas, entre outros.

O projeto de Lei da Doula visa além de sua aprovação proporcionar a discussão acerca da humanização do parto que se insere no contexto da luta pelo fim da violência contra a mulher, ao evidenciar a importância da atuação das doulas para diminuir os altos índices de violência obstétrica, dos excessos de cesarianas desnecessárias, e das outras práticas que causam efeitos físicos e psíquicos irreparáveis.

Várias cidades e Estados brasileiros já se mostraram favoráveis à aprovação da Lei pela Câmara dos Deputados, mas optaram por agir autonomamente acelerando seu processo de aplicação. Após o início das pesquisas, em Franca, a ideia que se tinha sobre doulas estava presente em um projeto de Lei, durante as evoluções das pesquisas a Lei se tornou realidade, sendo aceita e atualmente aplicada na cidade.

A transformação legislativa sobre o tema aqui colocado na cidade sede desta pesquisa comprova sua relevância jurídica. Durante exposições sobre o tema, muitas vezes aconteceram questionamentos sobre o objetivo de se fazer uma pesquisa a respeito da humanização dos partos e Lei da Doula, finalizar o trabalho desenvolvido pontuando esta questão é de suma importância.

Enquanto estudantes de Direito, as mulheres vivenciam diariamente um ambiente machista dentro de suas faculdades. A maioria dos professores são homens, a maioria dos alunos são homens e são estes que criaram a maioria de nossas leis e tomarão a maioria das decisões jurídicas de nosso país. Exceto se nos posicionarmos enquanto mulheres acadêmicas de Direito e possuidoras de direitos.

Não basta estar no ambiente acadêmico se a presença da mulher neste não for utilizada como "arma de combate". Falar sobre Lei da Doula é falar sobre resistência feminina, é divulgar dentro da academia machista um tema que trata de direitos específicos da mulher e defendê-lo, comprová-lo e efetivá-lo.

Isto posto, considera-se a iniciação científica de tema "Adoção do Parto Humanizado" um avanço pessoal e social dentro da Faculdade de Direito de Franca, tema de grande relevância 


\section{jurídica, social e humana e que a partir desta se inseriu nas salas e debates da instituição.}

\section{REFERÊNCIAS BIBLIOGRÁFICAS}

AGÊNCIA FIOCRUZ DE NOTÍCIAS. Nascer no Brasil: pesquisa revela número excessiva de cesarianas. Disponível em: <http://portal.fiocruz.br/pt-br/content/pesquisa-revela-numero-excessivode-cesarianas-no-pais>. Acesso em: 7 de abril de 2017.

BALOGH, Giovanna. Conheça a lei que permite a entrada de doulas em hospitais. Disponível em: <http://www.maesdepeito.com.br/conheca-as-leis-que-permitem-a-entrada-de-doulas-em-hospitais/>. Acessado em: 8 de março de 2018.

Banco de Teses, CAPES (Coordenação de Aperfeiçoamento de Pessoal de Nível Superior). Disponível em: <hp://bancodeteses.capes.gov.br/banco-teses/\#/>. Acesso em 7 de abril 2017.

BLOG A VIOLÊNCIA OBSTÉTRICA. Os números da violência obstétrica. Disponível em: <https://aviolenciaobstetrica.wordpress.com/dados-estastisticos-violencia-obstetrica/>. Acessado em: 17 de maio de 2018.

BORGES, João Paulo. Lei das Doulas de SC é referência para outros estados. Disponível em: <http://www.vermelho.org.br/noticia/281275-1>. Acessado em: 18 de março de 2018.

BRASIL. Câmara dos Deputados. Projeto de Lei nº 8.363, de 2017. Disponível em: < https://goo.gl/Tzpg9E>. Acessado em: 18 de março de 2018.

CÂMARA MUNICIPAL DE FRANCA. Gestantes terão direito a doulas em hospitais. Disponível em: <http://site.camarafranca.sp.gov.br/noticias/2017/03/gestantes-terao-direito-a-doulas-emhospitais>.Acessado em: 20 de abril de 2018.

CAMPELO, Lilian. Pará: Lei garante a presença de doulas em maternidades em Belém. Disponível em: <https://www.brasildefato.com.br/2017/06/13/para-lei-garante-a-presenca-de-doulas-emmaternidades-em-belem/>. Acessado em: 14 de março de 2018.

CORRÊA, Elídia Aparecida de Andrade; GIACOIA, Gilberto; CONRADO, Marcelo. Biodireito e dignidade das pessoas humana. São Paulo: Juruá: 2009.

DESPERTAR O PARTO. Doula: o que é?. Disponível em: <http://www.despertardoparto.com.br/oque-eh-doula.html>. Acessado em: 10 de fevereiro de 2018.

DIAS, Tatiana. Por que doulas se tornaram pivôs em brigas com entidades médicas. Disponível em: $<$ https://www.nexojornal.com.br/expresso/2016/03/26/Por-que-doulas-se-tornaram-piv\%C3\%B4sem-brigas-com-entidades-m\%C3\%A9dicas>. Acessado em: 15 de julho de 2018.

EQUIPE HANAMI. A história do parto. Disponível em: <http://www.equipehanami.com.br/ahistoria-do-parto/>. Acessado em: 20 de junho de 2018. 
FREIXAS, Meritxell. O abuso silenciado que há por trás das cesáreas. Disponível em: <https://brasil.elpais.com/brasil/2017/08/24/actualidad/1503582688_802126.html〉. Acessado em: 17 de julho 2018.

FRUTUOSO, Letícia Demarche; BRUGGEMANN, Odaléa Maria. Conhecimento sobre a Lei 11.108/2005 e a experiência dos acompanhantes junto à mulher no centro obstétrico. Texto contexto enferm., Florianópolis, v. 22, n. 4, p. 909-917, Dec. 2013. Disponível em:

$<$ http://www.scielo.br/scielo.php?script=sci_arttext\&pid=S0104-

07072013000400006\&lng=en\&nrm=iso>. Acessado em: 12 de junho de 2018.

G1. Sancionada lei que permite doulas em hospitais em Juiz de Fora. Disponível em: <http://g1.globo.com/mg/zona-da-mata/noticia/2016/12/sancionada-lei-que-permite-doulas-emhospitais-em-juiz-de-fora.html>. Acessado em: 12 de junho de 2018.

LARRAZ, Irene. Por que a cesária se tornou um bom negócio na América Latina? Disponível em: < https://brasil.elpais.com/brasil/2017/08/09/actualidad/1502268381_004054.html>. Acessado em: 20 de abril de 2018.

MORAES, Eleonora. O que é Parto Humanizado? Disponível em:

<http://www.despertardoparto.com.br/o-que-e-parto-humanizado.html>. Acessado em: 2 de abril de 2018.

LEÃO, Gabriel. A mulher negra é a que mais sofre no Brasil com violência no parto. Disponível em: $<$ https://www.vice.com/pt_br/article/gv35vw/dados-violencia-no-parto-brasil >. Acessado em: $17 \mathrm{de}$ maio de 2018.

ORGANIZAÇÃO MUNDIAL DA SAÚDE. Declaração da OMS sobre taxa de cesáreas. Disponível em:

<http://apps.who.int/iris/bitstream/handle/10665/161442/who_rhr_15.02_por.pdf;jsessionid=66798F A97BB367D27B30AE34A719CE42? sequence=3 >. Acessado em: 3 de março de 2018.

RATTNER, Daphne; BELKINS, Trench. Humanizando nascimentos e partos. São Paulo: Senac, 2005.

SABATINO, Hugo \& DUNN, Peter. Parto Humanizado: Formas Alternativas. São Paulo: Unicamp, 1992.

BRASIL. Lei 11.108/2005

Senado Federal, Sistema RVBI (Rede Virtual de Bibliotecas). Disponível em:

<hp://biblioteca2.senado.gov.br:8991/F/?func=find-d-0>. Acesso em 7 de abril 2017.

VIEIRA, Elisabeth Meloni. A medicalização do corpo feminino. São Paulo: Fiocruz, 2002.

Zanardo, G. L. P., Calderón, M., Nadal, A. H. R., \& Habigzang, L. F. Violência obstétrica no Brasil: uma revisão narrativa. Disponível em: <http://www.scielo.br/pdf/psoc/v29/1807-0310-psoc-29e155043.pdf $>$. Acessado em: 20 de maio de 2018. 